\title{
EL PADRE SARMIENTO Y EL MEGALITISMO GALLEGO
}

\author{
MARCOS MARTINÓN-TORRES*
}

\section{Resumen}

Se recogen y analizan, dentro de su contexto histórico, las referencias del Padre Fray Martín Sarmiento (1695-1772) al megalitismo gallego. A partir de ellas se estudia su aportación al conocimiento de este fenómeno y se comprueba cómo él inaugura la consideración de los monumentos como verdaderos documentos que informan sobre el pasado. Finalmente, se presenta una tabla con sus alusiones más específicas a monumentos megalíticos que podría facilitar eventuales trabajos de prospección arqueológica.

\section{Palabras Clave}

Megalitismo. Historiografía. Padre Martín Sarmiento.

\begin{abstract}
In this paper, the observations made by Father Martín Sarmiento (1695-1772) upon the megalithic complex in Galicia are collected and analysed in their historical context. On this basis, his contribution to our knowledge of this phenomenon is discussed, and it is argued that he was the first scholar to consider the monuments as actual sources of information about the past. Lastly, a table with his references to specific megaliths and their location is presented, in the hope that this could be of use for modern archaeological surveys.
\end{abstract}

\section{Key Words}

Megaliths. Historiography. Father Martín Sarmiento.

* Fue el Prof. Antón A. Rodríguez Casal, miembro del Insituto de Estudios Gallegos «Padre Sarmiento», quien, hace algunos años, me dio a conocer la afición megalitista de aquel fraile polifacético. A él debo agradecer la primera orientación.

Por razones de índole técnica y ajenas a mí, este artículo fue escrito y presentado en 1999 pero no ha podido ser publicado hasta ahora. Por ello, no he tenido ocasión de consultar o hacer referencia a los diversos estudios de y sobre Sarmiento publicados con posterioridad a esa fecha. 


\section{INTRODUCCIÓN: LOS PRIMEROS LIBROS DE HISTORIA O EL MEGALITISMO IGNORADO}

Nadie duda al reconocer en el Padre Fray Martín Sarmiento (1695-1772) a uno de los intelectuales más lúcidos y completos de la Historia de Galicia. Son conocidas sus aportaciones en campos tan diversos como la Filología, la Botánica, la Historia, la Geografía... y sus indagaciones en cada una de esas ramas del saber han sido objeto de distintos análisis por parte de investigadores actuales.

Sin embargo, no todas las facetas de su erudición han sido convenientemente analizadas todavía, y así sucede con el tema que aquí nos ocupa. En este artículo pretendemos argumentar la condición de pionero que tuvo este benedictino en el conocimiento del megalitișmo gallego. Ya Rodríguez Casal había señalado la atención prestada por el Padre Sarmiento a las mámoas del Barbanza y del Val do Salnés (Rodríguez Casal, 1990: 23; 1993: 56). Ahora, examinando con más detalle su actitud y sus reflexiones ante el fenómeno megalítico, descubriremos globalmente otro ámbito de la cultura en el que fue capaz de adelantar a sus contemporáneos $\mathrm{y}$, por tanto, otro campo en el que los especialistas deben empezar a reconocer su legado.

Para introducir nuestro trabajo debemos retrotraernos a los comienzos del siglo XVI, cuando aparecen en Galicia los primeros libros de Historia. Si queremos valorar en su justa medida el avance que representa Sarmiento en la investigación sobre el fenómeno megalítico gallego debemos empezar por advertir que, antes de él, no encontramos referencias al megalitismo gallego en ninguna obra de temática histórica. Desde el siglo XVI, la necesidad de legitimación de la nobleza gallega integrada en la Corte de Castilla, la lucha por el voto en Cortes, y la reacción contra la opinión popular y la literatura españolas, que hacían dibujos irrisorios de los gallegos, habían determinado el carácter marcadamente apologético de las primeras producciones históricas sobre Galicia (Barreiro, 1988). Con ellas se pretendía defender la antigüedad de la población gallega y de sus «puros» linajes aristocráticos, así como convertir Santiago de Compostela en el centro de la cristiandad occidental, y para estos fines no se dudaba en recurrir a la manipulación de etimologías, a la readaptación de pasajes bíblicos, al uso de falsos cronicones o a la más simple y pura fantasía. Sin embargo, parece que a estos primeros historiadores no se les ocurre emplear los restos arqueológicos para recrear ese pasado fabuloso, y por eso no hay en sus obras lugar para el megalitismo'.

${ }^{1}$ De manera amplia, se enmarcan en esta línea las obras de Vasco de Aponte, el Licenciado Molina, Ambrosio de Morales, Jernónimo del Hoyo, el Padre Gándara, Pascasio de Seguín o el Padre Flórez (cfr. Martinón-Torres, 2001b).

Cuadernos de Estudios Gallegos, Tomo LI, Fascículo 117, Santiago 2004. (Págs. 435 - 448) 
No debemos suponer que la no inclusión de los monumentos megalíticos en los primeros libros de Historia fuese debida al desconocimiento. Antes bien, nos inclinamos a pensar que los megalitos, tan repartidos por el suelo gallego, eran bien conocidos por casi todos los paisanos. Posiblemente lo que ocurría era que estos monumentos y los relatos a ellos asociados estaban todavía integrados plenamente en el acervo de lo mítico: eran obras de mouras, lugares de encantos... (Llinares, 1990; Alonso, 1998) y, en este sentido, no tenían cabida en unos libros que, aun bastante fantasiosos, pretendían guardar una apariencia de rigor. En el siglo XVII, en el proceso judicial que protagonizará el Licenciado Vázquez de Orjas por la destrucción furtiva de cientos de túmulos en busca de tesoros, las mámoas aparecen ya consideradas como «tumbas de gentiles galigrecos», pero todo lo que interesa de estos antepasados son las riquezas que pudieron dejar, y todavía no se atiende en absoluto al papel que podrían haber desempeñado en la Historia de Galicia (Martinón-Torres, 2001b:80-120; 2002). Esta línea de desatención hacia el papel histórico y documental del monumento megalítico llegará hasta mediados del siglo XVIII.

\section{EL CAMBIO DE ACTITUD: RACIONALISMO Y ENCICLOPEDISMO}

El panorama empieza a cambiar a medida que llegan a Galicia los aires de la Ilustración. Con la Ilustración llega el racionalismo y, con el racionalismo, la lucha contra la superstición. En ese contexto, si liberamos al megalito del aura mítica que lo rodea, de la superstición, de la credulidad, de la fantasía... nos queda entonces un monumento desnudo, una construcción que no es más -ni menos- que un vestigio del pasado. En un paseo típicamente ilustrado, el Padre Juan Sobreira, libre ya del apasionamiento mítico, tenía el cuidado de apuntar la existencia de restos arqueológicos en un lugar. Estas anotaciones «redúcense á sinxela mención de tres castros e de varias mámoas nos termos xurisdiccionaes da parroquia de Santa María da Capela» (López Cuevillas, 1933: 35), pero resultan indicativas de un cambio de mentalidad con respecto al vestigio prehistórico. Ahora bien, será el Padre Sarmiento quien se encargue sistemáticamente de filtrar los megalitos por el tamiz de la razón. Y sólo desde esta perspectiva podrá empezar a descubrirse el fenómeno megalítico en su dimensión informativa.

Pero aún hay otra virtud singular en Martín Sarmiento que facilitará este paso: nos referimos a su enciclopedismo. Una extraordinaria voluntad de saber, en todos los campos, con independencia de que sus conocimientos pudiesen tener o no aplicación práctica, caracteriza a un Sarmiento que, de este modo, se desmarca del

Cuadernos de Estudios Gallegos, Tomo LI, Fascículo 117, Santiago 2004. (Págs. 435 - 448) 
pragmatismo alguna vez definido como «característica común a los pensadores ilustrados gallegos» (Dopico, 1984: 234). Así, dejando a un lado el mero pragmatismo utilitarista, el Padre Sarmiento podrá observar con detenimiento unos monumentos megalíticos que no por carecer de utilidad práctica directa carecían también de interés.

En suma, tenemos que, unidos en su persona, el racionalismo de su tiempo y este amplio enciclopedismo serán los factores que abran el camino para un conocimiento cabal de nuestro fenómeno megalítico.

\section{EL MEGALITISMO GALLEGO EN LAS OBRAS DEL PADRE SARMIENTO}

Para aproximarnos al conocimiento que tuvo Fray Martín Sarmiento del megalitismo debemos prescindir de la imagen que de él se nos transmite a veces, la de un monje con tendencia al aislamiento y al sedentarismo (p.e. Barreiro, 1991: 321). Tras una juventud azarosa y un tanto viajera, Sarmiento pasó, entre 1728 y 1745 , por una etapa de encierro y reposo, en la que se dedica a leer y a escribir. Sin embargo, después de este período, se hace consciente de que la vida debe llenarse de experiencias y de que, para extraer el máximo rendimiento de ellas, conviene fiarse poco de la memoria propia y confiar los recuerdos e impresiones al papel escrito. De este modo, a partir de entonces elaborará libros de viajes y obras de carácter geográfico-histórico que aquí nos interesan especialmente, pues es en ellas donde encontraremos sus ideas sobre el megalitismo.

Los Viajes a Galicia de 1747 y 1754-55 (publicados en 1975 y 1950, respectivamente) son ya trabajos de un hombre maduro y minucioso que nos lega riquísimos conocimientos de Botánica, Geografía, Etnografía, Filología, Historia... y también referencias y comentarios sobre monumentos megalíticos.

El Problema Chorográfico para describir Galicia con un nuevo método (publicado en 1997) surge como iniciativa privada del autor y es complemento de las obras anteriores, en la medida en que sus experiencias viajeras le servirán de ayuda. La obra, escrita probablemente en 1762, nunca fue terminada, pero contamos con una edición de los textos escritos al respecto antes de su brusca interrupción. Sabemos, además, que en 1741 había ideado un proyecto semejante para recorrer y describir América (Pensado, 1984: 83), y Villa-amil nos menciona un «Método de pasear y patear todo el Reyno de Galicia» que también suponemos precedente de este Problema Chorográfico (Villa-amil, 1875: 62). El objetivo que se planteaba era «formar un grandísimo mapa de Galicia que no tenga igual en los libros, en

Cuadernos de Estudios Gallegos, Tomo LI, Fascículo 117, Santiago 2004. (Págs. 435 - 448) 
cuanto al exacto, cierto, universal, individual, sin que ningún sitio se coloque a bulto en el dicho mapa» (PC, 28v. $)^{2}$. Para llevar a cabo su ingente propósito, el Padre Sarmiento se proponía seguir un nuevo método ideado por él mismo: «andar todos los perfiles o orillas de toda el agua dulce y salada que hay en todo el Reino de Galicia» (PC, 29v.). La descripción, con admirables aspiraciones de exhaustividad, no sólo habrá de apuntar los datos más estrictamente geográficos o topográficos sino detenerse también en cada puente, casa, ermita, fortificación, castillo..., así como en inscripciones, sepulcros antiguos, letreyros y mámoas.

Finalmente, en nuestro rastreo por las obras de Sarmiento buscando megalitos, debemos pararnos también en un Manuscrito cuyo original desconocemos, pero que aparece transcrito, un siglo más tarde, en la Historia de Martínez de Padín (1850). Los datos e interpretaciones que nos ofrece, algunos de los cuales aparecerán ratificados en otras obras suyas, son también de un valor incuestionable.

Analizando el contenido de estas obras, comprobamos cómo el Padre Sarmiento personifica una nueva mentalidad, una nueva actitud intelectual que lleva a considerar los restos arqueológicos -incluidos los megalitos- como interesantes testimonios de nuestro pasado, liberándose de fábulas y de vanas aspiraciones de riqueza. Con él se hace patente el inicio de la valoración arqueológica, ese papel de documento histórico que ahora comienza a otorgarse al megalito.

En primer lugar debemos aludir a su interés por describir las mámoas y sus hipótesis acerca del proceso constructivo de las mismas, pues nos revelan ya la consideración del objeto arqueológico per se, como realidad que merece ser observada:

«... Unas piedras artificialmente puestas, o en círculo unas inclinadas a otras, $y$ que en el centro se hallaban, cabando, unas ollas de barro con cenizas». (v1754, 24).

"Un montecillo artificial de tierra y de figura circular, de unos 15 o 20 pies de diámetro. Vg. en un campo echo mucha tierra, y esta la reduzgo a la figura de una tarima redonda, que representa un montecillo, mámoa (o teta), que se eleve cuatro o seis pies; en el centro encaxo tres, cuatro o cinco losas de punta, que dexen espacio en el medio, y en el centro de ese espacio está enterrada la olla cineraria, y tierra por encima». (V1754, 25).

«También es natural que primero plantasen las losas verticales y después formasen alrededor la mámoa amontonando la tierra...» (V1754, 26).

\footnotetext{
${ }^{2}$ En adelante nos referiremos a las obras de Sarmiento con abreviaturas: V1745=Viaje de 1745; V1754= Viaje de 1754; $\mathrm{PC}=$ Problema Chorográfico $; \mathrm{M}=$ Manuscrito . Después de la coma se indica el número de folio o página.
} 
Su observaciones son tan precisas que atienden, incluso, a la orientación de los monumentos:

«Noté que las mámoas que he visto miran al mar occidental, hacia donde los gentiles suponian estar los Campos Elysios». (PC, 68v.).

Ante una serie de vestigios materiales de estas características, Sarmiento, como es habitual en sus trabajos, comienza por buscar luz en los nombres de los objetos a estudiar, en lo que J. L. Pensado llama con acierto «etimología iluminadora» (Sarmiento 1975: 26):

"La voz mamoa es comunísima en Galicia, y tiene dos significaciones, una de cosa natural y otra de cosa artificial. Del origen mamma, que significa teta se derivó mammilla $y$ de manmula diminutivo, y en la media edad otro diminutivo menor mammulella mamolilla. De la voz mámmula se formó a la castellana mamola y de mamolella mamolilla. Asi mamolas en castellano y mamoas en gallego, son unos montones naturales de tierra o de piedras que prepresentan la figura de una pirámide roma y redonda, y á los cuales llaman también los franceses mamelles». (M, 73).

«...Y porque alrededor de estos dichos sepulcros se amontonaba tierra en forma de mambla, de ahi vino el llamarlos mamoas o mámulas». (V1754, 25-26).

"Anta es 'peña derecha'». (V1745, 126r.).

También conservamos disquisiciones etimológicas de lo que pudieran ser menhires prehistóricos: «A todo llama Parafita sin duda de perafita y esto de pedra fita». (V1747, 130r.).

Pero el intelectual ilustrado debe ir más allá en el plano de la interpretación, y la interpretación rigurosa debe apartarse de la conjetura carente de fundamentos. Para ello, el primer paso es una crítica lúcida contra cuantas ensoñaciones y mitos puedan obstruir nuestro conocimiento. En diversos lugares se ha valorado que Sarmiento, en contraste con Feijoo, se preocupó más por recoger y documentar los usos y creencias populares que por erradicarlos (Pensado, 1984: 83; Barreiro, 1991: 323). Sin embargo, esta afirmación debe matizarse ante la tajante censura ejercida por nuestro monje sobre las concepciones populares que, como vemos, rodeaban a las mámoas gallegas. Bastante elocuente es su afirmación: «Moras encantadas en Galicia es la más fatua credulidad que se puede imaginar». (PC, 67v.)

Y si no son personajes fantásticos quienes realizaron los túmulos, no podemos esperar, tampoco, encontrar tesoros encantados en su interior, cosa que hacen «los avarientos ignorantes y ociosos» ( $\mathrm{PC}, 66 \mathrm{v}$.):

Cuadernos de Estudios Gallegos, Tomo LI, Fascículo 117, Santiago 2004. (Págs. 435 - 448) 
«La tontería y ambición las llama minas, tambien, porque los embusteros persuaden a los ricos avarientos, que en ellas hay grandes tesoros». (M, 74).

«... No quiero que los viajeros den oídos a la simpleza de que en tal y en tal parte hay un tesoro encantado». (PC, 67v.).

"Y como los embusteros no hallaron sino cascos de ollas y carbones, y tal cual vez piedras escritas, que ni saben leer ni sueñan apreciar, salen burlados y burlan a los demás... Asi se entiende el proverbio latino thesaurus carbones erant... Pues los que en esos sepulcros busquen tesoros sólo hallarán carbones y cenizas». (M, 74).

El Padre Sarmiento es contundente en estos fragmentos reproducidos. Como ilustrado, confía en el progreso, que puede perfeccionar la naturaleza humana sin modificarla, mediante una mera depuración de la ignorancia, la pasión y la superstición. Este enfoque evolucionista y optimista del cambio cultural no se opone a la idea cristiana tradicional ni a la idea cartesiana de una naturaleza humana fija e inmutable. Por eso, Sarmiento, con una convicción tan propicia, no debe dejar de contribuir a ese progreso. Y su firmeza es muestra del esfuerzo que supone su pionera actitud «científica», con vistas a evitar la intromisión de lo irracional en un conocimiento que debe ser racional. Hasta este punto, Sarmiento ha dado ya dos pasos de científico: la observación objetiva y la refutación de un conocimiento no contrastado. Mas su labor sigue, ya que, si bien no merece la pena perder el tiempo buscando tesoros, sí «se podrán utilizar mucho estas mámoas, para averiguar antigüedades» (V1754, 26). Es más:

"Con ellos se podrá adelantar la geografia, la antigüedad y la historia, y suplir mucho que no consta de los autores antiguos que se conservan. Y no hallo dificultad en decir que también se restaurarán muchas voces de la lengua latina que se han perdido». (M, 74).

Asimismo, otra idea que se desprende de su trabajo y que no debe dejar de mencionarse es su percepción del papel del megalito como marcador territorial, una utilidad práctica posiblemente heredada del Neolítico, constatada ya para la Edad Media, y que a la altura del siglo XVIII no se ha perdido (Martinón-Torres, 2001a). Sarmiento señalaba ya la frecuencia de la utilización del término manmula en «término por donde pasa apeo, ó demarcación en los privilegios» (M, 73), refiriéndose a los documentos antiguos. Pero, además, ya en su tiempo, reconoce: «Pedrafita... se llamará asi por aquella peña fita, que parece 'marco'o 'marcón', $y$ de hecho alli se dividen algunas feligresias». (V1745, 158r.).

Cuadernos de Estudios Gallegos, Tomo LI, Fascículo 117, Santiago 2004. (Págs. 435 - 448) 
Avalados por todos estos datos, no podemos dejar de insistir en la ruptura que supone la voz del Padre Sarmiento en la Galicia de su tiempo. Podemos afirmar que con sus declaraciones queda definitivamente inaugurada una postura ante el vestigio prehistórico en la que, de un modo genérico, todavía nos enmarcamos los arqueólogos de doscientos cincuenta años después.

Ahora bien, Sarmiento también se equivoca, cosa en absoluto sorprendente si se tiene en cuenta el nulo desarrollo de la investigación arqueológica en la Galicia de su tiempo. Su confusión, como puede intuirse, se da en el último escalón de sus deducciones: ¿a quién atribuir la autoría de los megalitos? Nuestro ilustrado cree que a los romanos. En su opinión, los túmulos son sepulcros colectivos con las urnas cinerarias de los romanos, y así lo manifiesta en numerosas ocasiones. Recogemos como muestra los siguientes párrafos, en los que elabora una hipótesis interpretativa de todo el proceso ritual:

"Asi estas dichas mámoas, que si se buscan habrá infinitas, son del tiempo de los romanos, cuando aún se quemaban los cuerpos por razón de hallarse en ellos las urnas cinerarias». (V1754, 26).

«Estas mamoas no son otra cosa sino los antiguos sepulcros de los romanos, en cuyo centro colocaban las ollas o urnas cinerarias. Escogian un sitio retirado en el campo y que tubiese leña: alli quemaban los cuerpos, recogían sus cenizas y las metian en una olla, y esta la enterraban allí cerca. Después, si habia piedra, fijaban al rededor y verticalmente algunas largas piedras ó losas, y al rededor de estas amontonaban mucha tierra... A la dicha tierra de la mamoa alude la deprecación sit tibi terra levis, y esta misma lei yo en una lápida que se desenterró de una mamoa...» (M, 73).

Con respecto a este párrafo debemos subrayar también la confusión patente entre las losas de las cámaras megalíticas y las lápidas funerarias verdaderamente romanas. Quizás podría sugerirse una amplitud semántica del término mámoa, que abarcase toda estructura funeraria supuestamente romana. Sin embargo, ya que hemos comprobado que el Padre Sarmiento es capaz de describir con precisión los túmulos que hoy reconocemos, no creemos que él mismo confundiese las mámoas con otros enterramientos; antes bien, pensamos que aquí se nos podría estar hablando de un hallazgo esporádico en el que nuestro fraile no estuvo presente, lo cual le lleva a la confusión. Este error estaría propiciado por la atribución cronocultural que se hace de las mámoas. Otra posibilidad sería que esa mámoa, en particular, sí que hubiese sido reutilizada por los romanos, como se documenta en algunos casos (p.e. Caamaño y Criado, 1991-92). 
Por otro lado, merece atención, además, la curiosa explicación que ofrece Sarmiento a la aparentemente desigual distribución en el espacio de los túmulos:

«... Las guerras las habrán arrasado todas. Y el haber tantas al norte de la ría de Padrón, y en especial hacia las costas, consiste en que hacia alli no ha habido guerras continuadas, ni disputas de principes sobre territorio». (PC, 68r.).

\section{TRASCENDENCIA}

Aunque es cierto que igual respeto merece la exactitud relativa de un texto histórico que la inexactitud relativa de un texto mítico, debemos reconocer al Padre Sarmiento una considerable labor de racionalización del conocimiento arqueológico. Aunque el folklore pervive aún hoy como una dimensión rica y muchas veces instructiva de la cultura, la postura de Sarmiento nos ubica, al menos, en una perspectiva más académica y con más visos de acercarnos a los retazos de verdad que hoy conocemos sobre las mámoas. A través de su obra nos acercamos a una nueva concepción del monumento prehistórico, una valoración del mismo como resto arqueológico que aún tardará en cuajar.

Sabemos que, hacia el final del siglo XVIII, Fray Pablo Rodríguez preparaba una Disertación acerca de las antigüedades de Galicia (cfr. Villa-amil, 1875: 68). Quizá esta obra suponía ya un paso más en la senda abierta por Sarmiento; tal vez en ella se analizaba el fenómeno megalítico gallego desde una perspectiva nueva. Sin embargo, no sabemos siquiera si la obra llegó a terminarse y, lo que se llegó a escribir, se ha perdido. Pero si queremos comprobar la trascendencia de las pioneras reflexiones de Sarmiento sobre el megalitismo gallego, basta hacer un recorrido sobre los principales libros de Historia que aparecerán en el siglo XIX (cfr. Martinón-Torres 2000a): Verea y Aguiar (1838) presentará una definición de los monumentos megalíticos que no es más que un calco de la que nos había brindado Sarmiento; asimismo, partirá del rechazo de la superstición y de las indagaciones etimológicas para tratar de profundizar en el conocimiento de este fenómeno. Más tarde, cuando Martínez de Padín (1849-50) quiera hablar de las mámoas, aportará ciertas reflexiones y una clasificación tipológica pero, sustancialmente, se limitará a transcribir, como ya indicamos, un manuscrito de nuestro benedictino. Finalmente, el gran Murguía $(1865,1888)$ también se remitirá a Sarmiento en muchos de sus pasajes (cfr. Martinón-Torres, 2000b).

La huella del Padre Sarmiento en el proceso de conocimiento del fenómeno megalítico gallego puede seguirse rastreando hasta la actualidad. Si bien sus 
imprecisiones han podido irse corrigiendo con el avance de la investigación, todos debemos a él una prístina voluntad de observar los monumentos desprovistos de fantasía y con vocación de historiadores. La idea de que a partir del megalito se puede conocer mejor el pasado nace, para Galicia, en este momento. Por la falta de investigaciones sobre el terreno, las hipótesis explicativas serán erróneas. En estos trabajos hay sesgos «de improvisación, de apriorismos y, aunque parezca paradójico, de excesivo racionalismo» (Barreiro 1991: 347). Pero esta disposición que parte de la razón y de la confianza en el progreso para explicar la realidad, sugiere el camino hacia la liberación del providencialismo divino y de la argumentación mítica para el conocimiento del pasado arqueológico. En este sentido, no podemos dejar de reconocernos sus herederos.

Mas no es sólo este el mérito que se debe reconocer a Sarmiento desde la Arqueología. El prehistoriador debe agradecerle también una nutrida serie de referencias a túmulos -entre otros restos arqueológicos-, muchos de ellos caracterizados con elementos geográficos y toponímicos que quizá nos permitan localizar, estudiar y conservar algunos de ellos. En ciertos casos, su testimonio es tan explicito que, probablemente, si las mámoas no han sido arrasadas, su localización no ofrecerá dificultad en un trabajo de prospección sobre el terreno. En el caso contrario, si estas mámoas no se conservan ya, constatar su existencia pretérita no deja de resultar de interés para reconstruir los paisajes prehistóricos:

«En el monte Sespon... se ven muchos sitios que no pueden menos de ser mámoas». (V1754, 25).

"En donde comienza la dicha ría [de Padrón], hacia Corrubedo, hay un campo que allí laman el Campo das Minas... poblado de mámoas. «(PC, 66 r.v.).

«...En el lugar de Moimenta río arriba del río Lérez de Pontevedra, hay cerca un campo de mamoas». (M, 75).

También facilitando nuestra prospección actual, aconseja Sarmiento que no se deje de visitar ningún lugar de Galicia llamado Oleiros, ya que, por lo general, y contra lo que se pudiera pensar, el topónimo no viene dado por el trabajo de ceramistas - «en ninguno hallé noticia de que alli se fabricasen ollas» (M, 74)sino a que allí había «ollarios», campos de urnas funerarias cubiertas por mámoas. Por ejemplo,

«... Oleyros cerca de Salvatierra del Miño, tiene muchas mamoas». (M, 74).

Cuadernos de Estudios Gallegos, Tomo LI, Fascículo 117, Santiago 2004. (Págs. 435 - 448) 
En otros casos, las alusiones no son tan claras o tan detalladas, pero siempre encontramos algún dato que quizás pudiera acercarnos a nuevos monumentos, por lo que todas las citas se hacen dignas de interés. Es por esto que, para finalizar, hemos recogido una lista con las alusiones más concretas del Padre Sarmiento a monumentos megalíticos o a lugares del territorio gallego que pudieran albergarlos. Estos datos pueden servir también como prueba de que la aportación de este «descubridor» del megalitismo gallego sigue siendo útil.

Tabla 1.

Monumentos megalíticos en las obras del Padre Sarmiento.

\begin{tabular}{|c|c|c|c|}
\hline Núm. & Fuente & Denominación & Localización-Cita Textual \\
\hline 1 & V1745, 49v. & Anta & $\begin{array}{l}\text { Per illam antam, quae stat in illo fontano... } \\
\text { de Villaverde (Lérez). }\end{array}$ \\
\hline 2 & V1745, 49v. & Antas & $\begin{array}{l}\text { Hay en Santiago de Antas, y otro Antas } \\
\text { feligresía cerca de Pontevedra. }\end{array}$ \\
\hline 3 & V1745, 183r. & Antas & Antas, aldea de Lebosán. \\
\hline 4 & V1745, 125v. & Antas & $\begin{array}{l}\text { Una ermita... de Santiago de Antas, siendo } \\
\text { así que allí no hay lugar de Antas. Pero lejos } \\
\text { de allí... una feligresía que llaman Santiago } \\
\text { de Antas. }\end{array}$ \\
\hline 5 & V1745, 91v. & Mámoa & $\begin{array}{l}\text { Entre la punta de Carreira y los bajos de } \\
\text { Curruvedo hay esto: mámoa, lugar. }\end{array}$ \\
\hline 6 & $\mathrm{~V} 1745,87 \mathrm{v}$ & Moimenta & Camino de Moimenta (Noya). \\
\hline 7 & V1745, 88r. & Moimenta & Moimenta, aldea, monte y cuesta horrorosa. \\
\hline 8 & V1745, 124r. & Moimenta & Moimenta, San Salvador, feligresía \\
\hline 9 & V1745, 130r. & Piedra Fita & $\begin{array}{l}\text { Chán de Piedra Fita, o de Justáns... se ven más } \\
\text { altos desde el puente de Pontevedra mirando } \\
\text { al surleste. }\end{array}$ \\
\hline 10 & V1745, 158r. & Parafita, Pedrafita & $\begin{array}{l}\text { Al venir yo de Justáns a Pontevedra por } \\
\text { Marcón [pasé por Parafita o Pedrafita, que] } \\
\text { se llamaría así por aquella peña fita. }\end{array}$ \\
\hline 11 & V1745, 191r. & Pedrafita & Sitios de la feligresía del Cebrero... Pedrafita. \\
\hline 12 & V1754, 25 & Mámoa & Que en Leiro avía una [mámoa]. \\
\hline 13 & V1754, 25 & Mámoa & $\begin{array}{l}\text { Antes de entrar en el Puente de Brea... había } \\
\text { unas [mámoas] a la izquierda. }\end{array}$ \\
\hline
\end{tabular}




\begin{tabular}{|c|c|c|c|}
\hline Núm. & Fuente & Denominación & Localización-Cita Textual \\
\hline 14 & V1754, 25 & Mámoa & $\begin{array}{l}\text { En la heredad... de don Felipe Romero de } \\
\text { Rianxo hay también otras dos o tres [mámoas]. }\end{array}$ \\
\hline 15 & V1754, 25 & Mámoa & $\begin{array}{l}\text { En el monte de Sespon... se ven muchos } \\
\text { sitios que no pueden menos de ser mámoas. }\end{array}$ \\
\hline 16 & $\mathrm{PC}, 46 \mathrm{v}$. & Antas & $\begin{array}{l}\text { A tres leguas al oriente de Pontevedra, en la } \\
\text { feligresía de Las Antas. }\end{array}$ \\
\hline 17 & $\mathrm{PC}, 59 \mathrm{r}$. & Parafita & $\begin{array}{l}\text { El primero [río Molinar] baja de lo alto } \\
\text { del monte elevadísimo de Perafita en Marcón. }\end{array}$ \\
\hline 18 & PC, 66r.v. & Minas; Mámoas & $\begin{array}{l}\text { En donde comienza la dicha ría [de Padrón], } \\
\text { hacia Corrubedo, hay un campo que allí } \\
\text { llaman el Campo das Minas... poblado de } \\
\text { mámoas. }\end{array}$ \\
\hline 19 & PC, $72 \mathrm{v}$. & Moimenta & $\begin{array}{l}\text { De Noya a Argalo [pasé por] cuesta de } \\
\text { Moimenta. }\end{array}$ \\
\hline 20 & $\mathrm{PC}, 74 \mathrm{r}$ & Moimenta & $\begin{array}{l}\text { [El trayecto fue] Amorín, Moimenta, } \\
\text { Randulfe... }\end{array}$ \\
\hline 21 & PC, 76r. & Medela & De aquí [Bayón] a Padrón [pasé por] Medela. \\
\hline 22 & $\mathrm{PC}, 76 \mathrm{r}$. & Mámoa & De aquí [Padrón] a Junquera, [...] Mámoa. \\
\hline 23 & $\mathrm{PC}, 79 \mathrm{r}$ & Parafita & $\begin{array}{l}\text { Desde Pontevedra a... Vilarchán, alto de } \\
\text { Parafita, Buchabad... }\end{array}$ \\
\hline 24 & $\mathrm{PC}, 82 \mathrm{r}$. & Parafita & Leboreyro, Grando, Parafita. \\
\hline 25 & $\mathrm{M}, 74$ & Minas; Mámoas & $\begin{array}{l}\text { Entre las rías de Pardrón y de Noya... [hay] } \\
\text { un páramo despoblado que llaman el Campo } \\
\text { das minas el cual he visto poblado de mamoas } \\
\text { sepulcrales. }\end{array}$ \\
\hline 26 & M, 74 & Mámoas & $\begin{array}{l}\text { En el lugar de Oleyros, cerca de la Puebla del } \\
\text { Dean... muchas mámoas }\end{array}$ \\
\hline 27 & M, 74 & Mámoas & $\begin{array}{l}\text { Y otro Oleyros cerca de Salvatierra del Miño, } \\
\text { tiene muchas mámoas }\end{array}$ \\
\hline 28 & M, 75 & Moimenta; Mámoas & $\begin{array}{l}\text { En el lugar de Moimenta, río arriba del río } \\
\text { Lérez de Pontevera, hay cerca un campo de } \\
\text { mámoas. }\end{array}$ \\
\hline
\end{tabular}




\section{BIBLIOGRAFÍA}

ALONSO ROMERO, F. (1998): «Las mouras constructoras de megalitos: estudio comparativo del folklore gallego con el de otras comunidades europeas». Anuario Brigantino, 21: 11-28.

BARREIRO FERNÁNDEZ, X.R. (1984): «La historia de la Historia: aproximación a una historiografía gallega (siglos XVI-XIX». In X. Castro y J. de Juana (eds.): IV Xornadas de Historia de Galicia. Historiografia galega. Deputación Provincial de Ourense. Ourense: 15-80.

BARREIRO FERNÁNDEZ, X.R. (1991): La Galicia del Antiguo Régimen. Enseñanza, ilustración y política. In F. Rodríguez Iglesias (ed.): Galicia. Historia. Vol. IV. Hércules de Ediciones. A Coruña.

CAAMAÑO GESTO, J.M. y CRIADO BOADO, F. (1991-2): «La medorra de Fanegas (Sobrado dos Monxes, A Coruña). Un monumento megalítico reutilizado en época romana». Brigantium, 7: 7-89.

DOPICO, F. (1984): Voz «Ilustración». In Gran Enciclopedia Gallega. XVII: 233-237. Silverio Cañada Editor. Gijón.

LÓPEZ CUEVILlAS, F. (1933): «Prehistoria de Melide». In R. Otero Pedrayo (dir.): Terra de Melide. Seminario de Estudios Galegos. Santiago de Compostela.

LLINARES GARCÍA, M. (1990): Os mouros no imaxinario popular. Servicio de Publicacións e Intercambio Científico da Universidade de Santiago de Compostela. Santiago de Compostela.

MARTÍNEZ PADÍN, L. (1849-50): Historia politica, religiosa y descriptiva de Galicia. Establecimento Tipográfico de A. Vicente. Madrid. 2 vols.

MARTINÓN-TORRES, M. (2000a): «Análisis del 'megalitismo céltico' en la Galicia del siglo XIX». Gallaecia, 19:287-309.

MARTINÓN-TORRES, M. (2000b): «Murguía e a arqueoloxía galega». Boletín da Real Academia Galega. 361: 221-244.

MARTINÓN-TORRES, M. (2001a): «Los megalitos de término. Crónica del valor territorial de los monumentos megalíticos a partir de las fuentes escritas». Trabajos de Prehistoria, 58 (1): 95-108.

MARTINÓN-TORRES, M. (2001b): Os monumentos megaliticos despois do Megalitismo. Arqueoloxía e Historia dos megalitos galegos a través das fontes escritas (s. VI - s. XIX). V Premio de Investigación Xesús Ferro Couselo. Concello de Valga. Valga.

MARTINÓN-TORRES, M. (2002): «Defying God and the King: a $17^{\text {th }}$-century gold rush for 'megalithic treasure'». Public Archaeology, 2 (4): 220-235.

MURGUÍA, M. (1865): Historia de Galicia, vol. 1 (1 ${ }^{\mathrm{a}}$ ed.). Imprenta de Soto Freire, Lugo.

MURGUÍA, M. (1888): Galicia (1 ${ }^{\mathrm{a}}$ ed.). In España. Sus monumentos y artes. Su naturaleza é Historia. Establecimiento Tipográfico - Editorial de Daniel Cortezo y $\mathrm{C}^{\mathrm{a}}$. Barcelona.

PENSADO, J.L. (1984): Voz «Sarmiento, Fray Martín». In Gran Enciclopedia Gallega, XXVIII: 82-84. Silverio Cañada Editor. Gijón. 
RODRÍGUEZ CASAL, A.A. (1990): O megalitismo. A primeira arquitectura monumental de Galicia. Servicio de Publicacións e Intercambio Científico da Universidade de Santiago de Compostela. Santiago de Compostela.

RODRÍGUEZ CASAL, A.A. (1993): «Análise historiográfica do megalitismo galego». In J. G. Beramendi (coord.): Galicia e a Historiografia. Tórculo. Santiago de Compostela: 53-71.

SARMIENTO, M. (1950a): Manuscrito. In L. Martínez Padín: Historia politica, religiosa y descriptiva de Galicia. Establecimiento Tipográfico de A. Vicente. Madrid. Vol. 2: 73-75

SARMIENTO, M. (1950b): Viaje a Galicia (1754). Anejo 3 de Cuadernos de Estudios Gallegos. C.S.I.C. e Instituto Padre Sarmiento de Estudios Gallegos. Santiago de Compostela.

SARMIENTO, M. (1975): Viaje a Galicia (1745). Museo de Pontevedra y Secretariado de Publicaciones e Intercambio Científico de la Universidad de Salamanca. Salamanca.

SARMIENTO, M. (1996): Problema Chorográfico para describir Galicia con un nuevo método. In Escritos Geográficos. Xunta de Galicia, Consellería de Cultura. Santiago de Compostela.

VEREA Y AGUIAR, J. (1838): Historia de Galicia. Primera parte, que comprende los origines y estado de los pueblos septentrionales y occidentales de la España antes de su conquista por los romanos. Imprenta de D. Nicasio Taxonera. Ferrol.

VILLA-AMIL Y CASTRO, J. (1875): Ensayo de un catálogo sistemático y crítico de algunos libros, folletos y papeles asi impresos como manuscritos que tratan en particular de Galicia. Imprenta de T. Fortanet. Madrid. 